\title{
COVID-19: Physical Inactivity and Diabetes
}

\author{
Luis Tomás Ródenas Cuenca* \\ School of Sports Organization, Autonomous University of Nuevo Leon, México
}

*Corresponding author: Luis Tomás Ródenas Cuenca, School of Sports Organization, Autonomous University of Nuevo Leon, San Nicolás de los Garza 66455, México.

To Cite This Article: Luis Tomás Ródenas Cuenca. COVID-19: Physical Inactivity and Diabetes. 2020 - 9(5). AJBSR.MS.ID.001429.

DOI: 10.34297/AJBSR.2020.09.001429.

Received: 制 July 10, 2020; Published: 眥 July 28, 2020

\begin{abstract}
The disease caused by SARS-CoV-2 has become a pandemic due to its rapid spread and transmissibility. Among the most vulnerable patients are older adults and those with chronic diseases, such as high blood pressure and diabetes mellitus. The prevalence of diabetes mellitus in Mexico is $10.3 \%$, a considerable figure if we take into account that these are people who know they have the disease. Therefore, the objective of the article is to present an overview and an analysis regarding the epidemiology and consequences of physical inactivity and sedentarism, the main effects of isolation, the benefits of exercise well prescribed in diabetic persons under the current COVID-19 pandemic.
\end{abstract}

Keywords: SARS-CoV-2, Distancing, Diabetes, Sedentary Lifestyle

\section{Introduction}

In December 2019, the first cases of unknown pneumonia were detected in the city of Wuhan, China, subsequently identified as a new coronavirus ( $\mathrm{CoV}$ ) virus, referred to by the International Committee on Virus Taxonomy as acute respiratory syndromecoronavirus 2 (SARS-CoV-2) [1,2]. Consequently, the disease was named by WHO as coronavirus 2019 (COVID-19). Since then it has spread rapidly in the rest of the world. Faced with this situation on 11 March 2020, the World Health Organization declared that COVID-19 was characterized as a pandemic. As of July 8, 2020, 11.8 million confirmed cases of COVID-19 infected have been reported worldwide, 6.42 million recovered and 544,000 deaths [3]. The most commonly reported symptoms are fever, cough, myalgia or fatigue, pneumonia and complicated dyspnoea, while less common symptoms include headache, diarrhea, hemoptisis, nasal discharge and productive cough $[4,5]$.

\section{Diabetic's Physical inactivity and COVID-19}

Preventive measures that have been taken include social distancing or isolation, hand washing, and the use of face masks [4].
This isolation could promote sedentary behavior, reduce regular physical activity and avoid daily activities (such as shopping or the park), which increases the risk of developing diseases or worsening previous pathologies. Generally speaking, remaining inactive during isolation for more than 2 or 3 weeks decreases major determinants of health, such as muscle strength and cardiorespiratory fitness (maximum oxygen consumption) that are predictors of cardiovascular mortality [6-9]. As a result, sedentary and physically inactive people should move more, and active and non-sedentary people should continue to exercise with variations at home during isolation. Physical inactivity generates 3. 2 million deaths worldwide, becoming the fourth global mortality risk factor also being one of the main risk factors for cardiovascular disease, cancer and diabetes $[10,11]$.

The WHO indicates that at least $60 \%$ of the world's population does not engage in the physical activity needed to obtain health benefits [12]. A recent analysis with 168 countries (1. 9 million participants) on global trends in insufficient physical activity (failure to comply with recommendations for at least 150 minutes 
of moderate-intensity physical activity or 75 minutes of vigorous intensity per week, or any equivalent combination of both), reported that in 15 years the overall pattern of physical activity has changed little, although inactivity has increased in high-income countries, and found in 2016 a global prevalence standardized by age of $27.5 \%$. The geographical area with the highest prevalence of inactivity is Latin America and the Caribbean (43.7\%). The prevalence of obesity ranges from $4 \%$ in Japan and Korea, to $30 \%$ or more in the U.S. and Mexico, but there is a global trend to increase in most regions by 2020 [13,14].

Type II Diabetes Mellitus (DM2) is a pathological entity with a high global representation, including a set of metabolic diseases, characterized by the presence of elevated blood glucose levels, also called hyperglycemia and which may be caused by poor insulin secretion, a resistance to the action of this, or a mixture of both [15]. Diabetes is one of the most common diseases in people with COVID-19, with a prevalence ranging from 7 to $30 \%$. In a metaanalysis of 12 studies in Chinese population, with an average age of 49.6 years, the prevalence of diabetes was $10.3 \%$, superior to the prevalence of diabetes in Chinese population adjusted by age. The probability of developing a severe case and entering intensive care unit is more than double in people with diabetes and the mortality described is up to three times higher $[16,17]$.

Consequently, the physical activity, diet, and pharmacological management, are fundamental in the treatment of DM2 being the first two being a personal and cultural responsibility, avoiding harmful lifestyles for health [18-20]. The current pandemic scenario can promote impaired control in people with diabetes due to difficulties in accessing the health system, lack of physical activity and increased stress associated with isolation. Strategies should therefore aim at facilitating access to the health system through telemedicine to advise on the adaptation of treatment or any other remotely manageable medical situation, and to guide patients and caregivers in the control of diabetes in sickness to prevent hospitalization. According to the International Diabetes Federation in 2011, there were nearly 366 million diabetics worldwide and it is estimated that by 2030 this number will increase by $51 \%$. This increase is related to obesity and physical activity patterns. It is shown in the reproductive age population, mainly in high-risk groups of developmental diabetes mellitus type 2 (DM2), that lifestyle changes such as regular exercise, healthy weight and eating behavior, can prevent their development [21-23].

In view of all of the above, the improvement of physical activity at this time of pandemic should be changed for activities at home in order to improve cardiorespiratory, muscle and bone health functions and reduce the risk of depression. The physical goals recommended by WHO for adults aged 18 to 64, accumulate a minimum of 150 minutes per week of moderate aerobic physical activity, or 75 minutes of vigorous aerobic physical activity each week, or an equivalent combination of moderate and vigorous activities [24]. Aerobic activity should be carried out in sessions lasting at least 10 minutes. In order to obtain even greater health benefits, adults in this age group increase the practice of moderate aerobic physical activity to 300 minutes per week, or up to 150 minutes per week of vigorous aerobic physical activity, or an equivalent combination of moderate and vigorous activity. Twice or more a week, carry out strengthening activities of large muscle groups [24]. It is clear that, in order to optimize the results of a healthy habit improvement program, you should increase the time and level of physical activity, decrease sedentary behavior, exercise, promote adherence to interventions and improve the components of fitness related to health: cardiorespiratory resistance, muscle strength, muscle endurance, flexibility, neuromotor control and body composition [25].

\section{Conclusion}

Under today's conditions, and because technology allows us, the current situation represents a very good opportunity to learn more about our health care. Another suggestion during isolation, to avoid some consequences of loneliness and try to maintain a routine, is to take advantage of virtuality to perform activities of various kinds such as work, study, leisure, eSports. In any case, the increase in sedentary behavior and inactivity should be avoided, due to its described consequences. In addition to maintaining ergonomic recommendations in different situations (postures, movements, distances), taking active pauses and respecting maximum screen times to avoid eye and general effects, such as computer syndrome [26-27].

\section{Conflict of Interest}

The author certify that they have no affiliations with or involvement in any organization or entity with any financial interest in the subject matter or materials discussed in this manuscript.

\section{Reference}

1. Lake MA (2020) What we know so far: COVID-19 current clinical knowledge and research. Clin Med (Lond) 20(2): 124-127.

2. Bao Y, Sun Y, Meng S, Shi, J, Lu L, et al. (2020) 2019-nCoV epidemic: address mental health care to empower society. Lancet 395(10224): e37-e38.

3. (2020) Google news Coronavirus (COVID-19).

4. Adhikari SP, Meng S, Wu YJ, Mao YP, Ye RX, et al. (2020) Epidemiology, causes, clinical manifestation and diagnosis, prevention and control of coronavirus disease (COVID-19) during the early outbreak period: a scoping review. Infect Dis Poverty 9(1): 1-12.

5. Richardson S, Hirsch JS, Narasimhan M, Crawford JM, Mc Ginn T, et al. (2020) Presenting characteristics, comorbidities, and outcomes among 5700 patients hospitalized with COVID-19 in the New York City area. JAMA 323(20): 2052-2059.

6. Mc Guire DK, Levine BD, Williamson JW, Snell PG, Blomqvist CG, et al. (2001) A 30-year follow-up of the Dallas Bed Rest and Training Study: I. Effect of age on the cardiovascular response to exercise. Circulation 104(12): 1350-1357. 
7. Wall BT, Dirks ML, Snijders T, Senden JM, Dolmans J, et al. (2014) Substantial skeletal muscle loss occurs during only 5 days of disuse. Acta Physiological 210(3): 600-611.

8. García A, Cavero I, Ramírez R, Ruiz JR, Ortega FB, et al. (2018) Muscular strength as a predictor of all-cause mortality in an apparently healthy population: a systematic review and meta-analysis of data from approximately 2 million men and women. Arch Phys Med Rehabil 99(10): 2100-2113.

9. Imboden MT, Harber MP, Whaley MH, Finch WH, Bishop DL, et al. (2018) Cardiorespiratory fitness and mortality in healthy men and women. J Am Coll Cardiol 72(19): 2283-2292.

10. (2020) World Health Organization. Estrategia mundial sobre régimen alimentario, actividad física y salud.

11. Lee IM, Shiroma EJ, Lobelo F, Puska P, Blair SN, et al. (2012) Effect of physical inactivity on major non-communicable diseases worldwide: an analysis of burden of disease and life expectancy. Lancet 380(9838): 219-229.

12. (2020) World Health Organization. Estrategia mundial sobre régimen alimentario, actividad física y salud. Inactividad física: un problema de salud pública mundial.

13. Sassi F, Devaux M, Fisher H (2012) Obesity update 2012. Organization for Economic Cooperation and Development 1-7.

14. Guthold R, Stevens GA, Riley LM, Bull FC (2018) Worldwide trends in insufficient physical activity from 2001 to 2016: a pooled analysis of 358 population-based surveys with 1.9 million participants. The Lancet Global Health 6(10): e1077-e1086.

15. Fadini GP, Morieri ML, Longato E, Avogaro A (2020) Prevalence and impact of diabetes among people infected with SARS CoV-2. JAMA 25152523

16. Roncon L, Zuin M, Rigatelli G, Zuliani G (2020) Diabetic patients with COVID-19 infection are at higher risk of ICU admission and poor shortterm outcome. Journal of Clinical Virology 127: 104354
17. Singh AK, Gupta R, Ghosh A, Misra A (2020) Diabetes in COVID-19: Prevalence, pathophysiology, prognosis and practical considerations. Diabetes Metab Syndr 14(4):303-310.

18. Alpizar SM (2001) Guía para el manejo integral del paciente diabético. Edición, Manual Moderno, México, 285-6.

19. Vega-Franco MS (2002) Ideas, creencias y percepciones acerca de la salud. Reseña histórica. Salud Púbica de México 44(3): 258-265.

20. García VM (1998) El diabético optimista. Páginas de Salud Pública. Revista Salud Pública de México 40: 1-3

21. (2012) Diabetes Atlas. International Diabetes Federation, Belgium.

22. Márquez AJ, Ramón SG, Márquez TJ (2011) Actualidad en ejercicio y diabetes tipo 2(I). Archivos de Medicina del Deporte XXVIII(143): 45-55.

23. Garber CE, Blissmer B, Deschenes MR, Franklin BA, Lamonte MJ, et al. (2011) American College of Sports Medicine position stand. Quantity and quality of exercise for developing and maintaining cardiorespiratory, musculoskeletal, and neuromotor fitness in apparently healthy adults: guidance for prescribing exercise. Med Sci Sports Exerc 43: 1334-1359.

24. (2012) World Health Organization. Recomendaciones mundiales sobre actividad física para la salud.

25. Riebe D, Ehrman JK, Liguori G, Magal M (2018) American College of Sports Medicine (Eds.), ACSM's guidelines for exercise testing and prescription, $\left(10^{\text {th }}\right.$ edn) Wolters Kluwer, USA.

26. Patterson R, Mc Namara E, Tainio M, de Sá TH, Smith AD, et al. (2018) Sedentary behaviour and risk of all-cause, cardiovascular and cancer mortality, and incident type 2 diabetes: a systematic review and dose response meta-analysis. Eur J Epidemiol 33(9): 811-829.

27. Koyama T, Kuriyama N, Ozaki E, Tomida S, Uehara, R, et al. (2020) Sedentary time is associated with cardiometabolic diseases in a large Japanese population: a cross-sectional study. J Atheroscler Thromb. 